\title{
Variabilidade genética de duas variedades de tilápia nilótica por meio de marcadores microssatélites
}

\author{
Angela Aparecida Moreira( ${ }^{(1)}$, Alexandre Wagner Silva Hilsdorf(2), Juliana Viana da Silva(2) \\ e Vânia Ribeiro de Souza ${ }^{(2)}$
}

\begin{abstract}
(1)Universidade de São Paulo, Inst. de Ciências Biomédicas, Av. Prof. Lineu Prestes, s/no, Cidade Universitária, CEP 05508-900 São Paulo, SP. E-mail: zarpelon@usp.br (2)Universidade de Mogi das Cruzes, Núcleo de Ciências Ambientais, CEP 08780-911 Mogi das Cruzes, SP. E-mail: wagner@umc.br, juliana_umc@gmail.com, vania_rsouza@yahoo.com.br
\end{abstract}

\begin{abstract}
Resumo - O objetivo desse trabalho foi avaliar a variabilidade genética de duas variedades de tilápia nilótica (Oreochromis niloticus), Chitralada e Red Stirling, e de suas progênies submetidas a programas de melhoramento genético, em sistemas intensivos de cultivo por meio de marcadores microssatélites. Foram utilizados 30 animais de cada variedade parental, 30 animais híbridos $(\mathrm{CH})$, provenientes do cruzamento entre as variedades Chitralada e Red Stirling, e 30 animais (RR) provenientes do cruzamento entre os parentais da variedade Red Stirling. Utilizaram-se cinco microssatélites: UNH104, UNH108, UNH118, UNH222 e UNH231. Observaram-se baixos índices de endogamia, com valores de $\mathrm{F}_{\mathrm{IS}}$ negativo para as duas variedades e seus cruzamentos. Verificouse diferença genética entre as duas variedades, obtida pelo cálculo do índice de fixação de alelos $\left(\mathrm{F}_{\mathrm{ST}}=0,131 \mathrm{e}\right.$ $\left.\mathrm{R}_{\mathrm{ST}}=0,130\right)$. As variedades parentais Chitralada e Red Stirling apresentaram $24,4 \%$ de distância genética, o que se refletiu na presença de vigor híbrido com $23,5 \%$ de incremento em rendimento no plantel $\mathrm{CH}$.
\end{abstract}

Termos para indexação: Oreochromis niloticus, melhoramento genético, híbridos, endogamia.

\section{Genetic variability of two Nile tilapia strains by microsatellites markers}

\begin{abstract}
The objective of this work was to evaluate the genetic variability of two Nile tilapia strains (Oreochromis niloticus), Chitralada and Red Stirling, as well as its offsprings submitted to genetic enhancement programs, in intensive systems farming by microsatellites markers. Thirty individuals of each parental strain, 30 crossbred $(\mathrm{CH})$ individuals from Chitralada and Red Stirling strains, and 30 individuals from Red Stirling progeny (RR) were used. Five microsatellites loci were utilized: UNH104, UNH108, UNH118, UNH222 e UNH231. Low values of inbreeding were observed with a negative $\mathrm{F}_{\mathrm{IS}}$ in both strains and their crossings. Genetic differences between the two strains were detected through $\mathrm{F}_{\mathrm{ST}}=0.131$ and $\mathrm{R}_{\mathrm{ST}}=0.130$. The parental strains Chitralada and Red Stirling presented $24.4 \%$ of genetic distance, which produced $23.5 \%$ of hybrid vigor in the $\mathrm{CH}$ stock.
\end{abstract}

Index terms: Oreochromis niloticus, genetic improvement, hybrids, inbreeding.

\section{Introdução}

As tilápias são peixes de água doce, pertencentes à família Cichlidae, originárias da África (Appleyard et al., 2001); atualmente, são cultivadas em vários países do mundo (Dey \& Gupta, 2000). De acordo com Hilsdorf (1995), as tilápias exibem vantagens que as tornam um grupo de peixes de interesse mundial: alimentam-se da base da cadeia trófica, aceitam variedade de alimentos e apresentam resposta positiva à fertilização em viveiros. São bastante resistentes a doenças, ao superpovoamento e a baixos níveis de oxigênio dissolvido. Estão amplamente distribuídas pelo território brasileiro e são cultivadas nos mais diversos sistemas de produção.
A criação de tilápias no Brasil teve como marco inicial a introdução de um plantel de Tilapia rendalli, na década de 1950, seguida de uma nova introdução de tilápia nilótica em 1972. Nas últimas duas décadas, a produção aqüícola no Brasil cresceu de forma significativa; dados do Ibama (2005) revelam que a produção brasileira da aqüicultura continental, nos anos de 2002 a 2004, teve incremento de $18.065 \mathrm{t}$, tendo aumentado de $162.665,5$ para $180.730,5$ t. No Brasil, a produção de tilápia incrementou em $38,22 \%$ a produção total de pescado oriunda do cultivo. Entre os peixes cultivados, é a espécie que apresenta maior produção aqüícola, seguida da carpa, Cyprinus carpio (24,99\%), e do tambaqui, Colossoma macropomum $(13,98 \%)$. 
Embora cerca de 70 espécies de ciclídeos recebam a denominação de tilápia, somente Oreochromis niloticus, Oreochromis mossambicus, Oreochromis aureus, Tilapia rendalli e seus híbridos apresentam importância para aqüicultura mundial (Stickney, 1997). Oreochromis niloticus destaca-se entre as demais por exibir características de interesse zootécnico, tais como: crescimento rápido e rusticidade, carne de excelente qualidade, com boa aceitação no mercado consumidor, mais apropriada para a indústria de filetagem, o que a torna de grande interesse para a piscicultura.

Apesar da alta produção, as práticas de manejo podem levar à diminuição da variabilidade genética presente em reprodutores, seja por falta de planejamento dos programas de seleção genética, seja pelo uso de número reduzido de indivíduos como reprodutores, o que aumenta a probabilidade de endocruzamentos (Hilsdorf \& Dergam, 1999).

A caracterização da variabilidade genética, em plantéis de tilápia nilótica, é uma etapa importante para o estabelecimento de um programa de melhoramento genético dessa espécie (Mather, 2001). Marcadores microssatélites têm sido utilizados para o monitoramento genético em peixes, tais como, sistema de cruzamento, fluxo gênico e estrutura genética dos estoques (Yue \& Orban, 2002).

Esses marcadores também podem ser empregados para estimativas dos coeficientes de endocruzamento e parentesco. Possibilitam, ainda, o estudo de acasalamento em espécies de populações naturais, cujo comportamento reprodutivo é de difícil avaliação (Colbourne et al., 1996), e podem ser utilizados para identificar possíveis relações genéticas entre a geração parental e progênie (Fessehaye et al., 2006). A utilização de marcadores moleculares, aliada ao manejo reprodutivo adequado, pode contribuir para a redução da endogamia em programas de melhoramento genético (Bentsen \& Olesen, 2002).

O objetivo desse trabalho foi avaliar a variabilidade genética de duas variedades de tilápia nilótica (Oreochromis niloticus), Chitralada e Red Stirling, e de suas progênies submetidas a programas de melhoramento genético, em sistemas intensivos de cultivo, por meio de marcadores microssatélites.

\section{Material e Métodos}

Foram utilizados: 60 reprodutores de tilápia nilótica; 30 animais da variedade Chitralada, conhecida por tailandesa, desenvolvida no Japão e melhorada no Palácio Real de Chitral, na Tailândia, que foi introduzida no Brasil em 1996, a partir de alevinos doados pelo Asian Institute of Techonology (AIT) e, desde a última década, vem sendo submetida a processos de melhoramento genético; 30 reprodutores da variedade Red Stirling, um mutante de tilápia nilótica sem pigmentação, proveniente da Universidade de Stirling, Escócia (Hussain, 1994); 30 híbridos, provenientes do cruzamento Chitralada $\mathrm{x}$ Red Stirling $(\mathrm{CH})$; e 30 animais resultantes do cruzamento entre Red Stirling x Red Stirling (RR).

A amostragem foi realizada nos animais mantidos nas Fazendas Santa Inês e Rio das Pedras, em Itupeva, SP, Brasil. Os procedimentos moleculares de análise do DNA das amostras foram conduzidos no Laboratório de Genética de Peixes e Aqüicultura, da Universidade de Mogi das Cruzes, SP.

Para a extração do DNA, utilizou-se cerca de $1 \mathrm{~cm}^{2}$ de tecido, proveniente da nadadeira caudal, conservado em etanol $95 \%$ a $4^{\circ} \mathrm{C}$. A extração de DNA total foi feita conforme Taggart et al. (1992), modificado pelo uso de tampão STE ( $\mathrm{NaCl}$ 0,1 M, Tris-HCl 0,05 M e EDTA 0,001 M, pH 8). A integridade do DNA extraído foi verificada em gel de agarose $0,8 \%$, revelado com $0,71 / 4 \mathrm{~g} \mathrm{~mL}^{-1}$ de brometo de etídio, e a eletroforese foi conduzida em $84 \mathrm{~V}$, por $50 \mathrm{~min}$, em cuba horizontal, com tampão TAE $1 \mathrm{X}$ (Tris-acetato $0,04 \mathrm{M}$ e EDTA $1 \mathrm{mM}$ ).

Os loci utilizados foram escolhidos por seu nível de polimorfismo, de um painel de marcadores já estabelecidos (Kocher et al., 1998). Os primers utilizados e seus respectivos números de acesso no GenBank são: UNH104 - G12257; UNH108 - G12261; UNH118 G12271; UNH222 - G12373 e UNH231 - G12382.

Para as reações de PCR, foram utilizados: $1 \mu \mathrm{L}$ de tampão PCR 10x, $1 \mu \mathrm{L}$ de dNTPs 2,5 mM (dATP, dCTP, dTTP dGTP), $0,5 \mu \mathrm{L}$ de cada primer $\left(1 \mu \mathrm{g} \mu \mathrm{L}^{-1}\right), 0,2 \mu \mathrm{L}$ de Taq DNA polimerase, $2 \mu \mathrm{L}$ de DNA genômico (aproximadamente $25 \mathrm{ng}), 0,4 \mu \mathrm{L}$ de $\mathrm{MgCl}_{2}(2 \mathrm{mM}), 13,9 \mu \mathrm{L}$ de $\mathrm{H}_{2} \mathrm{O}$ Milli-Q, para um volume final de $20 \mu \mathrm{L}$ (termociclador PTC-0200 DNA Engine). O programa de amplificação consistiu nas seguintes condições: um ciclo de desnaturação a $94^{\circ} \mathrm{C}$, por $3 \mathrm{~min}, 30$ ciclos de $40 \mathrm{~s} \mathrm{a} 94^{\circ} \mathrm{C} ; 1,5 \mathrm{~min}$ à temperatura de anelamento, para cada primer microssatélite $\left(\mathrm{UNH} 104: 57^{\circ} \mathrm{C}, \mathrm{UNH} 108 \mathrm{e}\right.$ UNH118: $56^{\circ} \mathrm{C}, \mathrm{UNH} 222: 54^{\circ} \mathrm{C}$ e UNH231: $58^{\circ} \mathrm{C}$ ); 1,5 min a $72^{\circ} \mathrm{C}$ para a extensão; e o último ciclo de extensão por $10 \min$ a $72^{\circ} \mathrm{C}$.

A verificação da amplificação foi realizada por eletroforese em agarose $1 \%$, com tampão TAE $1 \mathrm{x}$ e 
$0,7 \mu \mathrm{g} \mathrm{mL}-1$ de brometo de etídio. Os produtos da amplificação foram submetidos à eletroforese em gel de poliacrilamida 10\%, corados com nitrato de prata (Blum et al., 1987). O tamanho dos fragmentos foi calculado com o programa Alpha Index 6.5, tendo-se utilizado como marcadores 10 pb DNA Ladder e 100 pb DNA Ladder.

Testes para verificação da hipótese nula de aderência ao equilíbrio de Hardy-Weinberg (EHW) foram conduzidos com o método de Monte Carlo (Guo \& Thompson, 1992), pelo uso do programa TFPGA 1.3 (Miller, 1997). Para cada alelo identificado, foram computados os valores das estatísticas F de Wright (Cockerham \& Weir, 1993), com os respectivos testes de permutação, a fim de se verificarem significâncias, por meio dos programas FSTAT 2.9.3.2 (Goudet, 2002) e Arlequin ver. 3.01 (Excoffier et al., 2006).

A diversidade genética (Nei, 1973), frequiências alélicas, número de alelos por locus (Kocher et al., 1998), heterozigosidade observada e a heterozigosidade esperada (Weir \& Cockerham, 1984) foram estimadas pelos programas FSTAT 2.9.3.2 (Goudet, 2002), Arlequin ver. 3.01 (Excoffier et al., 2006) e Genepop Software ver. 3.3 (Raymond \& Rousset, 1995). Os intervalos de confiança foram calculados por meio de procedimentos de reamostragem do tipo "bootstrap" sobre os loci, para obtenção da média, e por meio de "jackknifing" sobre as amostras para cada locus.

\section{Resultados e Discussão}

A perda substancial da variabilidade genética é esperada, em razão das características da reprodução da tilápia e do tamanho pequeno da população, quando não há um manejo genético adequado do plantel de reprodutores. Os níveis de variabilidade genética de uma população natural ou mesmo de um plantel de reprodutores pode ser medido não somente pela heterozigosidade observada (Ho), mas também pela sua diversidade alélica.

A análise dos cinco loci mostrou um total de 37 alelos com alto polimorfismo. Os níveis de variabilidade alélica, nos quatro plantéis, variaram entre o máximo de oito alelos para os loci UNH104 e UNH118, e o mínimo de sete alelos para os loci UNH108, UNH222 e UNH231 (Tabela 1). A maior diversidade alélica encontrada $(0,81)$ foi para o locus $\mathrm{UNH} 222$, e a menor diversidade alélica $(0,65)$ foi verificada no locus UNH118. O plantel de reprodutores da variedade Chitralada apresentou maior número de alelos, com média de 5,8, enquanto o menor número de alelos encontrado foi no plantel RR (Red Stirling x Red Stirling), com média de 4,8 alelos (Tabela 2). Esses valores evidenciam diversidade alélica semelhante, nas duas variedades parentais e no híbrido $(\mathrm{CH})$, o que indica que não ocorreu perda significativa de alelos na formação do plantel de reprodutores. Nos indivíduos RR, houve uma redução do número médio de alelos, que pode ser explicada pelo

Tabela 1. Marcadores moleculares, tamanho em pares de bases (pb), número de alelos, frequiência dos alelos e diversidade alélica de Oreochromis niloticus.

\begin{tabular}{lccc}
\hline Locus & $\begin{array}{c}\text { Tamanho dos } \\
\text { alelos }(\mathrm{pb})\end{array}$ & $\begin{array}{c}\text { Número } \\
\text { de alelos }\end{array}$ & $\begin{array}{c}\text { Diversidade } \\
\text { alélica }\left(\mathrm{G}_{\mathrm{ST}}\right)\end{array}$ \\
\hline UNH104 & $130-160$ & 8 & 0,$213 ; 0,154 ; 0,021 ; 0,158 ; 0,108 ; 0,167 ; 0,129 ; 0,050$ \\
UNH108 & $130-148$ & 7 & 0,$029 ; 0,067 ; 0,025 ; 0,092 ; 0,288 ; 0,129 ; 0,271$ \\
UNH118 & $153-195$ & 8 & 0,$021 ; 0,025 ; 0,133 ; 0,179 ; 0,413 ; 0,025 ; 0,038 ; 0,167$ \\
UNH222 & $162-199$ & 7 & 0,$142 ; 0,108 ; 0,150 ; 0,117 ; 0,150 ; 0,213 ; 0,121$ \\
UNH231 & $170-183$ & 7 & 0,$117 ; 0,183 ; 0,092 ; 0,283 ; 0,213 ; 0,063 ; 0,050$ \\
\hline
\end{tabular}

Tabela 2. Marcadores microssatélites, grupo de ligação correspondente (Lg), número de alelos por locus no plantel, número de alelos privativos por locus no plantel (entre parênteses) e número de animais genotipados por plantel (sobrescrito), das variedades de Oreochromis niloticus Chitralada e Red Stirling e dos animais provenientes dos cruzamentos Chitralada x Red Stirling $(\mathrm{CH})$ e Red Stirling $x$ Red Stirling (RR).

\begin{tabular}{lccccc}
\hline Locus & Lg & Chitralada & Red Stirling & CH & RR \\
\hline UNH104 & 1 & $6(2)^{30}$ & $6(2)^{30}$ & $6(2)^{30}$ & $4(2)^{30}$ \\
UNH108 & 2 & $4(2)^{30}$ & $5(1)^{30}$ & $4(2)^{30}$ & $4(2)^{30}$ \\
UNH118 & 7 & $6(2)^{30}$ & $5(1)^{30}$ & $6(0)^{30}$ & $6(0)^{30}$ \\
UNH222 & 2 & $6(0)^{30}$ & $7(0)^{30}$ & $7(0)^{30}$ & $7(0)^{30}$ \\
UNH231 & 6 & $5(1)^{30}$ & $5(1)^{30}$ & $6(0)^{30}$ & $7(0)^{30}$ \\
\hline Média & & $5,8(1,4)$ & $5,6(0,7)$ & $5,6(0,6)$ & 7 \\
\hline
\end{tabular}


efeito fundador na formação dos plantéis de reprodutores da variedade Red Stirling.

Em populações naturais de tilápia nilótica do Lago Victoria, as variações encontradas no número de alelos por locus foram de 3,8 a 7,6 (Fuerst et al., 2000). Melo et al. (2006) trabalharam com plantéis comerciais de tilápia e encontraram 39 alelos em cinco loci microssatélites; para os loci UNH104 e UNH108, relataram a ocorrência de nove e seis alelos, respectivamente. Rutten et al. (2004) avaliaram quatro variedades de tilápia nilótica e obtiveram de 5 a 7,5 alelos por locus microssatélite. Romana-Eguia et al. (2004) encontraram uma variação de 4,8 a 10 alelos por locus microssatélite. Esses resultados foram similares aos verificados no presente trabalho.

As medidas das heterozigosidades observadas (Ho), que representam o grau de diversidade gênica dos plantéis, foram superiores para o parental Red Stirling $(0,763)$, quando comparado à variedade parental Chitralada $(0,724)$. Os valores de Ho apresentaram desvio significativo de He (Tabela 3). Esse desvio é esperado em populações de cativeiro e também foi observado por Romana-Eguia et al. (2004) e Rutten et al. (2004).

Os valores de $F_{I S}$ que representam uma medida do desvio das frequiências genotípicas, em relação às frequiências panmíticas, expressas em termos de deficiência ou excesso de heterozigotos, e que também podem ser interpretados como coeficiente de endogamia $(f)$, foram variáveis e significativamente diferentes de zero $(\alpha=0,005)$, nas variedades e seus cruzamentos. Esses valores indicaram a ocorrência de excesso de heterozigotos em todos os plantéis. Melo et al. (2006) encontraram altos valores positivos de $\mathrm{F}_{\mathrm{IS}}$, o que expressa níveis de endogamia dentro de seis plantéis comerciais de tilápia estudados. Rutten et al. (2004) também encontraram valores de $\mathrm{F}_{\text {IS }}$ variáveis e significativamente diferentes de zero, em três variedades comerciais de tilápia nilótica.

Tabela 3. Heterozigosidade esperada $(\mathrm{He})$, heterozigosidade observada (Ho), índice de fixação ( $\left.\mathrm{F}_{\mathrm{IS}}\right)$ e significância de $\mathrm{F}_{\mathrm{IS}}$ das variedades de Oreochromis niloticus Chitralada e Red Stirling e dos animais provenientes dos cruzamentos Chitralada x Red Stirling $(\mathrm{CH})$ e Red Stirling x Red Stirling (RR).

\begin{tabular}{lcccc}
\hline Variedade & $\mathrm{He}$ & $\mathrm{Ho}$ & $\mathrm{F}_{\text {IS }}$ & $\mathrm{P}$ \\
\hline Chitralada & 0,794 & 0,724 & $-0,070$ & 0,001 \\
Red Stirling & 0,937 & 0,763 & $-0,216$ & 0,000 \\
CH & 0,909 & 0,746 & $-0,164$ & 0,000 \\
RR & 0,953 & 0,712 & $-0,324$ & 0,000 \\
\hline
\end{tabular}

Na variedade parental Red Stirling, essa retenção de heterozigosidade $(-0,216)$ também pode ser explicada pela relativa freqüência dos alelos, que contribuem de maneira mais predominante do que o número de alelos em um locus (Beaumont \& Hoare, 2003).

Quando o tamanho da população efetiva (Ne) é pequeno, mesmo em cruzamentos totalmente ao acaso, uma diminuição de heterozigose pode ocorrer. No presente estudo, os dados indicam que na produção de híbridos entre as duas variedades - e mesmo na produção de alevinos de plantéis de Red Stirling - o aumento de endogamia ou decréscimo de $\mathrm{Ne}$ foi aparentemente evitado. Isto também foi verificado por Rutten et al. (2004) na variedade GIFT. Os valores de FIS mostraram que o manejo genético-reprodutivo das variedades foi apropriado, no que diz respeito à manutenção da variabilidade dos plantéis, pois não há sinais de depressão por endogamia.

Segundo a AMOVA (Weir \& Cockerham, 1984; Excoffier et al., 1992) (Tabela4), grande parte da variabilidade genética está concentrada dentro dos plantéis $(87,25 \%)$, com menor porcentagem entre eles $(12,75 \%)$. As medidas do efeito da subdivisão populacional, que representa a redução da heterozigosidade em uma subpopulação em razão do efeito da deriva genética, e avalia a divergência genética total entre subpopulações, foi calculada por meio de três parâmetros: $\mathrm{F}_{\mathrm{ST}}=0,131$ (Wright, 1965), $\mathrm{R}_{\mathrm{ST}}=0,130$ (Slatkin, 1995) e $\mathrm{a}=0,128$ (Excoffier et al., 1992). Esses parâmetros apresentaram valores significativamente diferentes de zero $(\mathrm{p}<0,05)$ e, de acordo com Wright $(1978)$, indicam de moderada à alta separação genética entre as variedades. Essa separação pode ser o resultado do histórico diferencial de formação genética de ambas as variedades ao longo dos anos. Rutten et al. (2004) encontraram variação de moderada à alta na diferenciação genética entre as variedades AIT e GÖTT e, para as variedades GIFT e IDRC essa diferenciação foi relativamente baixa, o que confirma uma ancestralidade genética comum.

Tabela 4. Análise molecular de variância (AMOVA), para os plantéis das variedades parentais Chitralada e Red Stirling de Oreochromis niloticus ${ }^{(1)}$.

\begin{tabular}{lccrc}
\hline Causas da variação & GL & SQ & CV & PV \\
\hline Entre as variedades & 1 & 499,494 & 5,822 & 12,78 \\
Dentro das variedades & 85 & $4.180,828$ & 9,463 & 20,78 \\
Total & 86 & $4.680,322$ & 15,286 & \\
(1)Baseado em 1.023 permutações. & & &
\end{tabular}


Melo et al. (2006) encontraram baixa variabilidade genética nos plantéis, possivelmente associada à proporção desigual de machos e de fêmeas utilizados para a reprodução, ou seja, um pequeno número de casais utilizados como estoque de reprodutores. Romana-Eguia et al. (2004) também encontraram baixa diferenciação genética entre os plantéis de tilápia nilótica.

$\mathrm{O}$ uso de apenas cinco loci microssatélites revelou a presença de alelos privativos que, apesar de sua baixa frequiência, contribuíram para assegurar distância genética de 24,4\% (Nei, 1972).

Esses resultados validam o estudo de Moreira et al. (2005), que compararam o crescimento das variedades parentais Red Stirling e Chitralada e seus híbridos. Nesse estudo, os dados de peso vivo médio dos parentais Red Stirling e Chitralada, aos 120 dias de cultivo, foram de $330,58 \pm 10,42$ e $143,68 \pm 8,59 \mathrm{~g}$, respectivamente. Os dados de peso vivo médio dos híbridos revertidos, aos 130 dias de cultivo, foram de 299,22 $\pm 6,74 \mathrm{~g}$ ( ${ }^{\star}$ Chitralada x $ᄋ$ Red Stirling) e 286,62 $\pm 9,32 \mathrm{~g}$ (o Red Stirling $x$ + Chitralada).

Com esses resultados, pôde-se avaliar a ocorrência de um possível efeito de vigor de híbrido (Tave, 1992). O cálculo de heterose para os dados de ganho de peso foi de $23,5 \%$, isto é $\mathrm{H}>0 \%$, o que representa melhor desempenho dos híbridos, em relação à geração parental, em razão de um efeito de heterose.

$\mathrm{O}$ grau de heterose produzido em um cruzamento entre dois genitores depende da diferença da freqüência gênica entre eles, para os loci envolvidos na expressão de uma determinada característica (Falconer, 1987). Em tilápias, a expressão da heterose vem sendo documentada em trabalhos com cruzamentos intra-específicos e interespecíficos (Romana-Eguia \& Eguia, 1999; Dan \& Little, 2000). No presente estudo, a heterose foi observada em cruzamentos entre variedades de tilápia nilótica e corroborada pelos dados das análises moleculares.

Os resultados deste trabalho mostraram que a técnica de marcadores moleculares é uma ferramenta útil para avaliar plantéis de reprodutores em piscicultura. A base de dados genéticos, gerada pelos microssatélites, permite tomar decisões importantes em relação ao manejo reprodutivo e à intensidade de seleção que se pode aplicar sobre o plantel, e manter-se, com isto, níveis baixos de endogamia nas progênies produzidas, evitandose a médio e longo prazos os efeitos negativos sobre a produção decorrentes da depressão por endogamia.

\section{Conclusões}

1. A variabilidade genética das variedades avaliadas é alta.

2. A melhoria de desempenho zootécnico da progênie híbrida é resultado do vigor híbrido.

3. A manutenção de baixos índices de endogamia na progênie $F_{1}$, proveniente de cruzamentos entre Red Stirling, mostra que o manejo reprodutivo adequado pode evitar as conseqüências negativas da depressão por endogamia.

\section{Agradecimentos}

À direção da Royal Fish Ltda., pelo fornecimento dos animais utilizados neste trabalho; aos funcionários das Fazendas Santa Inês e Rio das Pedras, especialmente ao Sr. Gilmar Pessi e Sr. Adilson Feliciano Duarte, pelo apoio durante a realização das biometrias e manejo; à Fapesp e à International Foundation for Science, pelo apoio financeiro.

\section{Referências}

APPLEYARD, S.A.; RENWICK, J.M.; MATHER, P.B. Individual heterozygosity levels and relative growth performance in Oreochromis niloticus (L.) cultured under Fijian conditions. Aquaculture Research, v.32, p.287-296, 2001.

BEAUMONT, A.R.; HOARE, K. Genetic structure in natural populations. In: BEAUMONT, A.R.; HOARE, K. Biotechnology and genetics in fisheries and aquaculture. Oxford: Blackwell Science, 2003. p.47-72.

BENTSEN, H.B.; OLESEN, I. Designing aquaculture mass selection programs to avoid high inbreeding rates. Aquaculture, v.204, p.349-359, 2002.

BLUM, H.; BEIER, H.; GROSS, H.J. Improved silver staining of plant proteins, RNA and DNA in polyacrylamide gels. Electrophoresis, v.8, p.93-99, 1987.

COCKERHAM, C.C.; WEIR, B.S. Estimation of gene flow from F-statistics. Evolution, v.47, p.855-863, 1993.

COLBOURNE, J.K.; NEFF, B.D.; WRIGHT, J.M.; GROSS, M.R. DNA fingerprinting of bluegill sunfish (Lepomis macrochirus) using $(\mathrm{GT})_{\mathrm{n}}$ microsatellites and its potential for assessment of mating success. Canadian Journal of Fisheries and Aquatic Sciences, v.53, p.342-349, 1996.

DAN, N.C.; LITTLE, D.C. The culture performance of monosex and mixed-sex new-season and overwintered fry in the three strains of Nile tilapia (Oreochromis niloticus) in Northern Vietnam. Aquaculture, v.184, p.221-231, 2000.

DEY, M.M.; GUPTA, M.V. Socioeconomics of disseminating genetically improved Nile tilapia in Asia: an introduction. Aquaculture Economic and Management, v.4, p.5-12, 2000. 
EXCOFFIER, L.; LAVAL, G.; SCHNEIDER, S. ARLEQUIN version 3.01: an integrated software package for population genetics data analysis. Bern: University of Bern, Zoological Institute, 2006. Disponível em: <http://cmpg.unibe.ch/software/arlequin3>. Acesso em: 21 mar. 2007.

EXCOFFIER, L.; SMOUSE, P.E.; QUATTRO, J.M. Analysis of molecular variance inferred from metric distances among DNA haplotypes: application to human mitochondrial DNA restriction data. Genetics, v.131, p.479-491, 1992.

FALCONER, D.S. Introdução à genética quantitativa. Viçosa: UFV, 1987. 279p.

FESSEHAYE, Y.; EL-BIALY, Z.; REZK, M.A.; CROOIJMANS, R.; BOVENHUIS, H.; KOMEN, H. Mating systems and male reproductive success in Nile tilapia (Oreochromis niloticus) in breeding hapas: a microsatellite analysis. Aquaculture, v.256, p.148158, 2006.

FUERST, P.A.; MWANJA, W.W.; KAUFMAN, L. The Genetic history of the introduced Nile Tilapia of lake Victoria (Uganda E. Africa): the populations structure of Oreochromis niloticus (Pisces:Cichlidae) revealed by DNA microsatellite markers. In: INTERNATIONAL SYMPOSIUM ON TILAPIA IN AQUACULTURE, 5., 2000, Rio de Janeiro. Proceedings. Rio de Janeiro: Ista, 2000. p.30-40.

GOUDET, J. FSTAT: a program to estimate and test gene diversities and fixation indices (version 2.9.3.2). Lausanne: University of Lausanne, Department of Ecology \& Evolution, 2002. Disponível em: $<$ http://www2.unil.ch/popgen/softwares/fstat.htm>. Acesso em: 21 mar. 2007.

GUO, S.W.; THOMPSON, E.A. Performing the exact test of HardyWeinberg proportions for multiple alleles. Biometrics, v.48, p.361372, 1992.

HILSDORF, A.W.S. Genética e cultivo de tilápias-vermelhas: uma revisão. Boletim do Instituto de Pesca, v.22, p.73-84, 1995.

HILSDORF, A.W.S.; DERGAM, J.A. Depressão por endogamia: somente uma terminologia genética ou um fato na aquiicultura. Panorama da Aqüicultura, v.9, p.34-36, 1999.

HUSSAIN, M.G. Genetics of body color inheritance in Thai and Egyptian red tilapia strains. Asian Fisheries Science, v.7, p.215224, 1994.

IBAMA. Estatística da pesca 2004: Brasil: grandes regiões e unidades da federação. Brasília: Coordenação Geral de Gestão de Recursos Pesqueiros, 2005. 136p. Disponível em: <http:// www.ibama.gov.br/rec_pesqueiros/index.php?id_menu=93>. Acesso em: 21 mar. 2007.

KOCHER, T.D.; LEE, W.J.; SOBOLEWSKA, H.; PENMAN, D.; McANDREW, B. A genetic linkage map of a cichlid fish, the tilapia (Oreochromis niloticus). Genetics, v.148, p.1225-1232, 1998.

MATHER, P.B. Overview of fish genetics research at Queensland University of Technology. In: GUPTA, M.V.; ACOSTA, B.O. (Ed.). Fish genetics research in member countries and institutions of the International Network on Genetics in Aquaculture. Penang: ICLARM - World Fish Center, 2001. p.133-139.

MELO, D.C.; OLIVEIRA, D.A.A.; RIBEIRO, L.P.; TEIXEIRA, C.S.; SOUSA, A.B.; COELHO, E.G.A.; CREPALDI, D.V.;
TEIXEIRA, E.A. Caracterização genética de seis plantéis comerciais de tilápia (Oreochromis) utilizando marcadores microssatélites. Arquivo Brasileiro de Medicina Veterinária e Zootecnia, v.58, p.87-93, 2006.

MILLER, M.P. TFPGA: tools for population genetic analyses: a Windows program for the analysis of allozyme and molecular population genetic data. Logan, 1997. Disponível em: <http:// www.marksgeneticsoftware.net/tfpga.htm>. Acesso em: 21 mar. 2007.

MOREIRA, A.A.; MOREIRA, H.L.M.; HILSDORF, A.W.S. Comparative growth performance of two Nile tilapia (Chitralada and Red-Stirling), their crosses and the Israeli tetra hybrid ND 56. Aquaculture Research, v.36, p.1049-1055, 2005.

NEI, M. Analysis of gene diversity in subdivided populations. Proceedings of the National Academy of Sciences of the United States of America, v.70, p.3321-3323, 1973.

NEI, M. Genetic distance between populations. American Naturalist, v.106, p.283-292, 1972.

RAYMOND, M.; ROUSSET, F. Genepop (Version 1.2): population genetics software for exact tests and ecumenicism. Journal of Heredity, v.86, p.248-249, 1995.

ROMANA-EGUIA, M.R.R.; EGUIA, R.V. Growth of five Asian red tilapia strains in saline environments. Aquaculture, v.173, p.161170, 1999.

ROMANA-EGUIA, M.R.R.; IKEDA, M.; BAISAO, Z.U.; TANIGUCHI, N. Genetic diversity in farmed Asian Nile and red hybrid tilapia stocks evaluated from microsatellite and mitochondrial DNA analysis. Aquaculture, v.236, p.131-150, 2004.

RUTTEN, M.J.M.; KOMEN, H.; DEERENBERG, R.M.; SIWEK, M.; BOVENHUIS, H. Genetic characterization of four strains of Nile tilapia (Oreochromis niloticus L.) using microsatellite markers. Animal Genetics, v.35, p.93-97, 2004.

SLATKIN, M. A measure of population subdivision based on microsatellite allele frequencies. Genetics, v.139, p.457-462, 1995. STICKNEY, R.R. Tilapia update 1996. World Aquaculture, v.28, p.20-25, 1997.

TAGGART, J.B.; HYNES, R.A.; PRODÖUHL, P.A.; FERGUSON, A. A simplified protocol for routine total DNA isolation from salmonid fishes. Journal of Fish Biology, v.40, p.963-965, 1992.

TAVE, D. Genetics for fish hatchery managers. $2^{\text {nd }}$ ed. New York: Van Nostrand Reinhold, 1992. 415p.

WEIR, B.S.; COCKERHAM, C.C. Estimating F-statistics for the analysis of population structure. Evolution, v.38, p.1358-1370, 1984.

WRIGHT, S. Evolution and the genetics of population: volume 4: variability within and among natural populations. Chicago: University of Chicago Press, 1978. 590p.

WRIGHT, S. The interpretation of population structure by F-statistics with special regard to systems of mating. Evolution, v.19, p.395-420, 1965.

YUE, G.H.; ORBAN, L. Microsatellites from genes show polymorphism in two related Oreochromis species. Molecular Ecology Notes, v.2, p.99-100, 2002. 